\title{
Predatory interactions between Thermocyclops decipiens Kiefer (Cyclopoida : Copepoda) and two small cladocerans : behavior and prey post-encounter vulnerability
}

\author{
A. Andrade ${ }^{1}$, C. López ${ }^{1,2 *}$ \\ ${ }^{1}$ Departamento de Biología. Facultad Experimental de Ciencias. Universidad del Zulia. Apdo. 526. Maracaibo 4011-A. Venezuela. \\ 2 Present address : Limnology Laboratory. Department of Biology. Baylor University. Waco 76798. Texas. U.S.A.
}

\begin{abstract}
The predatory behavior of adult females of Thermocyclops decipiens in relation to two cladoceran prey, Ceriodaphnia cornuta and Diaphanosoma spinulosum, was analyzed by laboratory observations. The number of attacks, captures, and ingestions were quantified. Probabilities of capture after attack (C/A) and ingestion after capture (I/C) were calculated as indicators of prey post-encounter vulnerability. T. decipiens attacked, captured and ingested both cladoceran species, but vulnerabilities of prey were relatively low. C/A was higher in $C$. cornuta than in $D$. spinulosum. Larger individuals of $D$. spinulosum showed higher $\mathrm{C} / \mathrm{A}$ and I/C than smaller individuals but no effects of size were observed in C. cornuta. The ability of escape as well as the strength and shape of carapace, seem to partially explain differences in vulnerability among these species. Our results suggest that intensity of mechanical perturbations and other size-dependent factors, but not body size alone, could be important in determining post-encounter prey vulnerability among individuals of a same species.
\end{abstract}

Keywords : Predatory behavior, Thermocyclops, cyclopoid copepod, cladocerans, vulnerability.

\section{Introduction}

Although some papers have thoroughly described predatory behavior of freshwater cyclopoid copepods and vulnerability of their zooplankton prey, these studies mainly concerned the interactions between temperate prey assemblages and cyclopoid copepods of the genera Mesocyclops (Gilbert \& Williamson 1978, Jamieson 1980, Williamson \& Gilbert 1980, Williamson 1983, 1986, Chang \& Hanazato 2003), Acanthocyclops (Li \& Li 1979, Roche 1987, 1990) and Diacyclops (Lapesa 2002). Thermocyclops species are commonly dominant components in crustacean zooplankton assemblages from tropical freshwater bodies around the world (Reid 1989, Ueda \& Reid 2003). As in other cyclopoid copepods, adults of these species consume not only algae (Moriarty et al. 1973, Infante 1978, González 1998), but also nauplii, rotifers and cladocerans (Gras et al. 1971, Clarke 1978, Carvalho

\footnotetext{
* Corresponding author :

E-mails: carlos_lopez1@baylor.edu,clopez@luz.edu.ve
}

1984). Some species can exert an important impact of predation (eg. Blumenshine \& Hambright 2003). However, aspects related to predatory behavior and vulnerability of prey, which may to help to explain the patterns of predator selectivity and impact on prey populations (Kerfoot et al. 1980, Jamieson 1980, Williamson \& Gilbert 1980) have not been analyzed in any species of the genus.

The recent re-evaluation of the importance of omnivorous components in food webs through intraguild predation models (Holt \& Polis 1997, Hart 2002) and ideas regarding the contribution of omnivores to the stability of ecological communities (Fagan 1997) make it necessary to refocus attention towards predation by omnivorous copepod species in planktonic food webs. This is particularly true in freshwater tropical planktonic communities, where critical information about food webs is still insufficient. Studies on predatory behavior of cyclopoid copepods and their prey suggest that body size, strength and shape of carapace, speed swimming and escape response, and behavior of prey are the major determining factors of post-encoun- 
ter vulnerability (Li \& Li 1979, Williamson 1986, 1987, Gliwicz \& Umaña 1994, Chang \& Hanazato 2003). According to Roche (1987), prey body size (volume) is inversely related to success of attacks of cyclopoids and a threshold exists above which prey capture becomes difficult. Speed swimming, escape responses and special behavior as such "dead man response" also decrease the efficiency of attacks of cyclopoids (Li \& Li 1979, Williamson 1986). On the other hand, success of capture is affected by strength of carapace (Li \& Li 1979, Jamieson 1980, Williamson 1983, Roche 1990). Thus, soft-bodied preys are always ingested after capture, while preys with hard carapace are usually rejected. Body size and shape may also be important in this regard, whereby copepods, despite capturing prey, would be unable to properly manipulate (i.e. holding firmly) large or awkwardly shaped prey (Roche 1990).

In absence of age or size dependent responses of escape or special behavior, body size is particularly relevant. Because it is directly correlated to swimming speed, carapace strength, and handling time of prey $(\mathrm{Li}$ \& Li 1979, Roche 1990), body size alone could be a good predictor of success of attacks and captures by cyclopoids on individuals of the same or closely-related prey species. At least with regard to success of attacks, recent results seem to support this idea. Thus, Chang \& Hanazato (2003) found that vulnerability to attacks from Mesocyclops leuckarti on large Daphnia and Ceriodaphnia individuals is lower than on smaller individuals. Similarly, Lapesa et al. (2002) found that percentages of capture after attacks of $D$. bicuspidatus odessanus is inversely related to size in three sibling rotifer species.

In this paper, we analyzed of the predatory behavior of a cyclopoid copepod, T. decipiens Kiefer, and the vulnerability of individuals belonging to distinct size classes of two prey species, Ceriodaphnia cornuta Sars and Diaphanosoma spinulosum Herbst. Also, we evaluate the importance of body size on vulnerability to predation within prey species. These crustacean species frequently coexist in zooplankton assemblages from neotropical water bodies (Rocha et al. 1995, López et al. 2001). Laboratory observations were made in order to answer the following questions : What is the behavior of predator and prey in each others presence? what is the vulnerability of $C$. cornuta and D. spinulosum to predation by $T$. decipiens? and how does body size of prey affect vulnerability in the same prey species?

\section{Methods}

Cyclopoid copepod predators and cladoceran prey were collected from the lacustrine zone of Manuelote Reservoir (also called Socuy Reservoir), an eutrophic and oligomictic waterbody in western Venezuela (Soto et al. 1994, López et al. 2001), where they are dominant components of crustacean zooplankton community (López 1994, López et al 2001). Both copepod and cladoceran populations were reared in the laboratory $\left(26 \pm 2{ }^{\circ} \mathrm{C} ; 12: 12\right.$, light:dark) a few weeks before observations. Cladocerans were fed with the algae Chlorella sp. isolated from the reservoir and cultivated under similar conditions in the laboratory. Copepods were fed with Chlorella and natural zooplankton prey items isolated from Manuelote reservoir.

Before the behavioral observations, adult females of T. decipiens were isolated individually in a test tube with filtered reservoir water (Whatman GF/C) and deprived of food for 24 hours. A single adult female of T. decipiens and 4-5 individuals of each prey species were exposed and observed in a cylindrical glass chamber of $5 \mathrm{ml}$ filled with filtered reservoir water during 15 minutes. This chamber had a size sufficient for the complete chamber contents to be viewed under a stereoscopic microscope using dim light. We quantified the number of attacks (A), captures (C) and ingestions (I) and calculated probability of capture after attack $(\mathrm{C} / \mathrm{A})$, and probability of ingestion after capture (I/C), according to a general behavioral model previously used for predatory copepods (Williamson \& Gilbert 1980,Williamson 1987, Chang \& Hanazato 2003). Prey killed or damaged by predators but not ingested were recorded as injured (Chang \& Hanazato 2003). When T. decipiens did not attack the prey within 15 minutes, observation was stopped and the data were excluded from the analysis.

Forty adult females of $T$. decipiens were studied for each observational condition and two prey species and two body size categories in each prey species were compared. Size categories were separated by filtration through $300 \mu \mathrm{m}$ mesh. Individuals in good condition were picked up with a Pasteur pipette and body size was measured suspending individuals in very small drops of water and using a light microscope. Rate of attacks, captures and ingestions and mean probabilities for each group of predators tested under any one set of conditions were calculated. Differences between prey species and body sizes were analyzed by the Kolmogorov-Smirnov Test. All tests were realized at 0.05 significance level using the statistical software SPSS version 10 . 


\section{Results}

\section{General predatory behavior}

Mean body size of predator T. decipiens was $932 \pm$ $45 \mu \mathrm{m}$. C. cornuta were $256 \pm 40 \mu \mathrm{m}$ for smaller individuals and $548 \pm 53 \mu \mathrm{m}$ for larger individuals and differences between smaller and larger individual were highly significant (Kolmogorov-Smirnov Test, $\mathrm{Z}=$ $3.78, \mathrm{p}=0.001$ ). Values of $D$. spinulosum were $281 \pm$ $77 \mu \mathrm{m}$ for smaller individuals and $766 \pm 113 \mu \mathrm{m}$ for larger individuals. Also, differences between these values were highly significant (Kolmogorov-Smirnov Test, $\mathrm{Z}=4.47, \mathrm{p} \leq 0.001$ ).

Number of attacks, captures, ingestions and injuries are shown in Table 1. In general, adult females of $T$. decipiens attacked both cladoceran species, but these attacks finished differently in captures and ingestions. In both prey species, no injuries were observed. Partial ingestions were more frequent in $C$. cornuta and in larger individuals of both species (Table 1).

Table 1. Number of attacks, captures, ingestions and \% of partial ingestions quantified in this study.

\begin{tabular}{ccccc}
\hline Prey & Attacks & Captures & Ingestions & $\begin{array}{c}\text { Partial Ingestions } \\
(\%)\end{array}$ \\
\hline Ceriodaphnia cornuta & & & & \\
$\quad$ Small individuals & 246 & 182 & 29 & 17 \\
$\quad$ Large individuals & 249 & 187 & 20 & 25 \\
$\begin{array}{c}\text { Diaphanosoma spinulosum } \\
\text { Small individuals }\end{array}$ & 304 & 14 & 7 & 0 \\
$\quad$ Large individuals & 261 & 34 & 32 & 3 \\
\hline
\end{tabular}

Prey carapace remains showed differences in predator attack patterns among cladoceran prey. While in $C$. cornuta marked traces of attacks were found on the valves, these traces were found on the head and second antennae in D. spinulosum.

After some unsuccessful attacks, the copepod immediately attacked the prey again. T. decipiens attacked both actively moving prey and prey damaged after an attack. Although attacks after a loss were observed in both prey species, these were more frequently observed on $C$. cornuta. In this prey species, a few subsequent attacks after a second attack also were observed. Neither cladoceran prey showed "dead-man response" as a specialized escape behavior. D. spinulosum showed the typical "pause and jump" swimming pattern in which strong strokes often allowed them to escape. In C. cornuta, a "hopping" swimming pattern and more rapid swimming were observed as escape responses in the presence of the predator.

The values of attack rates were between 16.5 and 30.4 attacks/predator/hour (Fig. 1a). The attack rates a)

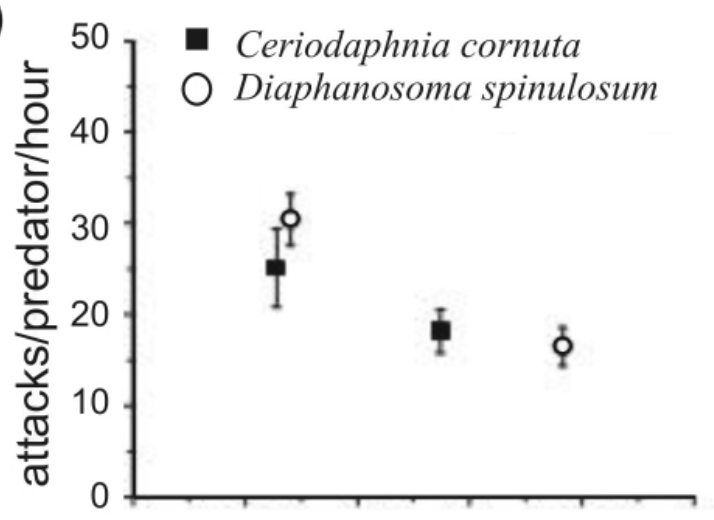

b)

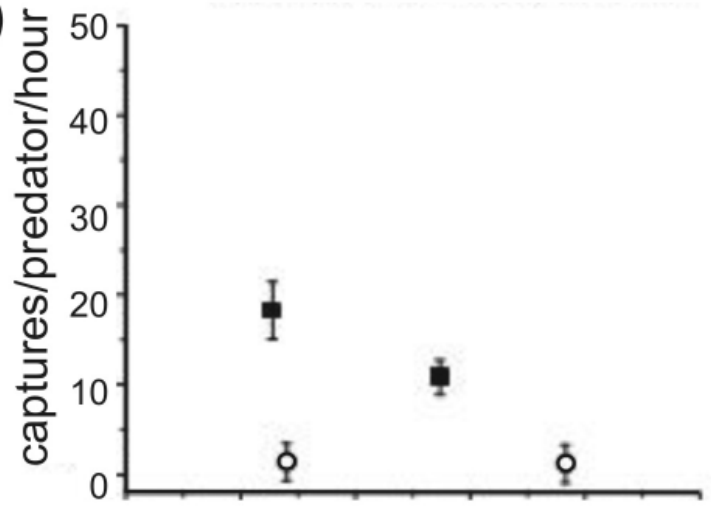

c)

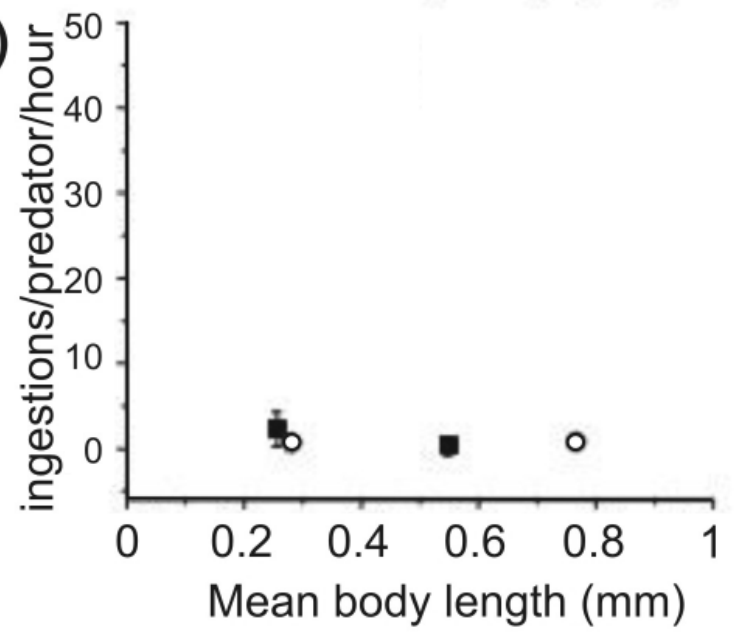

Fig. 1. a) Mean values of attack rates. b) Mean values of capture rates. c) Mean values of ingestion rates. Vertical bars represent standard errors. 
decreased in large individuals of both prey species. However, only in $D$. spinulosum differences between size classes were significant (Kolmogorov-Smirnov Test, $\mathrm{Z}=2.23, \mathrm{p} \leq 0.001)$. Similarly, differences between prey species were significant only in small individuals (Kolmogorov-Smirnov Test, $\mathrm{Z}=2.01, \mathrm{p} \leq$ 0.02). The capture rates were between 1.2 and 18.3 captures/predator/hour (Fig. 1b). No differences in capture rates between small and large individuals were found in both prey species. However, differences between prey species in the same size class were signifi-
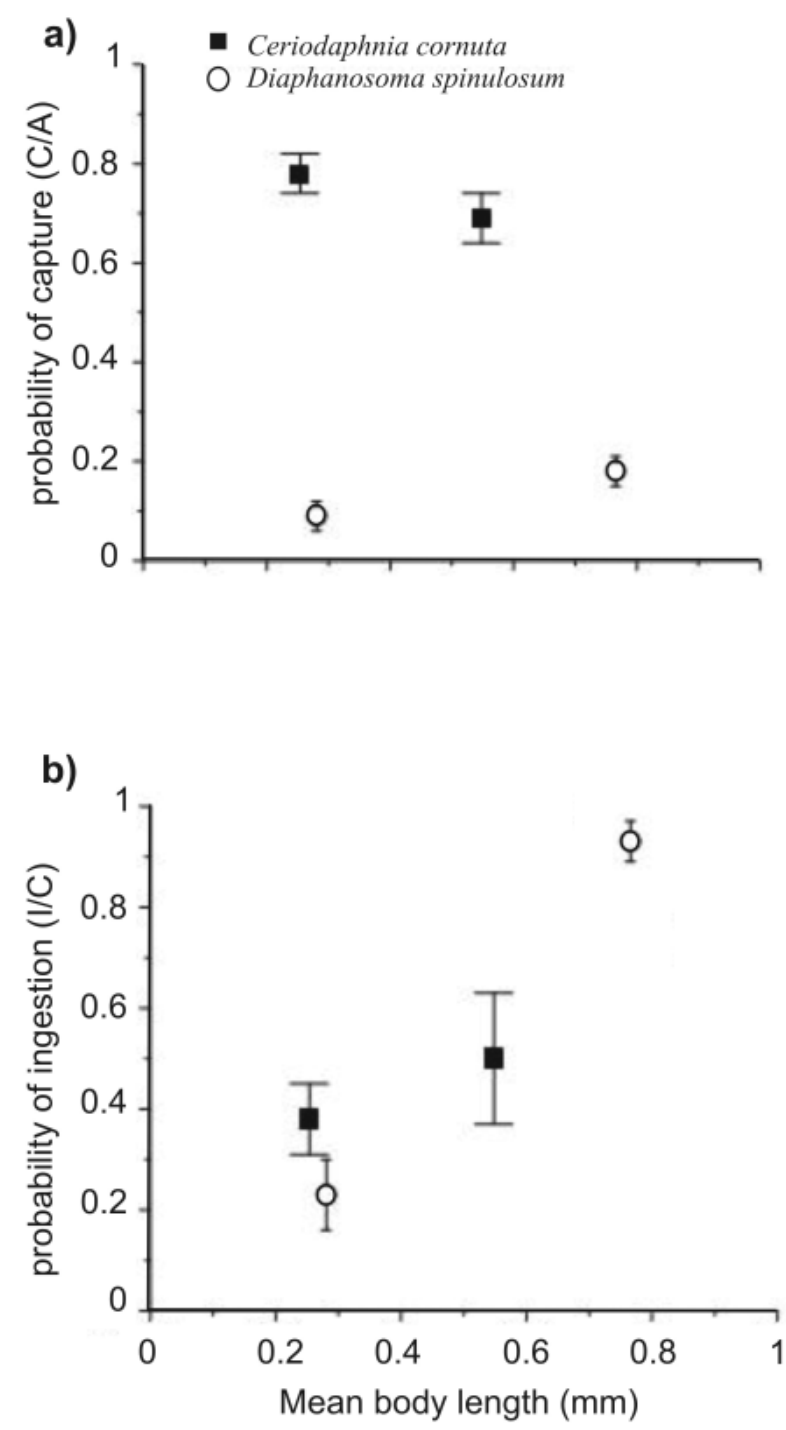

Fig. 2. a) Mean values of probability of capture after attack (C/A). b) Mean values of probability of ingestión after capture (I/C). Vertical bars represent standard errors. cant (Kolmogorov-Smirnov Test, $\mathrm{Z}=2.01, \mathrm{p} \leq 0.02$ for smaller individuals and $\mathrm{Z}=2.23, \mathrm{p} \leq 0.01$ for larger individuals). The ingestion rates were between 0.3 and 2.3 ingestions/predator/hour (Fig. 1c). Differences between size classes were significant only for $C$. cornuta (Kolmogorov-Smirnov Test, $\mathrm{Z}=2.34, \mathrm{p} \leq 0.001$ ) and between prey species only in small individuals (Kolmogorov-Smirnov Test, $\mathrm{Z}=1.79, \mathrm{p} \leq 0.03$ ).

\section{Prey vulnerability}

Mean C/A values of $T$. decipiens were higher for $C$. cornuta than for D. spinulosum (Fig.2a). In case of $C$. cornuta, values of C/A were higher than 0.6 , while these values were lower than 0.2 in D. spinulosum (Fig. 2). Kolmogorov-Smirnov Test showed that differences between prey species at the same size category were significant $(\mathrm{Z}=3.80, \mathrm{p} \leq 0.001$ and $\mathrm{Z}=1.68, \mathrm{p} \leq 0.01)$. In $D$. spinulosum, larger individuals showed higher mean values of $\mathrm{C} / \mathrm{A}$ than smaller individuals of the same species. Differences between larger and smaller individuals were significant for $D$. spinulosum (Kolmogorov-Smirnov Test $\mathrm{Z}=1.79, \mathrm{p} \leq 0.01$ ) but not for $C$. cornuta.

Except for larger individuals of $D$. spinulosum, mean values of I/C were lower than 0.6 (Fig. 2b). Smaller individuals of $C$. cornuta showed higher mean values of I/C than individuals of $D$. spinulosum of the same size category. These differences were significant (Kolmogorov-Smirnov Test, $\mathrm{Z}=2.61, \mathrm{p} \leq 0.01$ ). Inversely, larger individuals of $D$. spinulosum showed significantly higher mean values of $\mathrm{I} / \mathrm{C}$ than larger individuals of $C$. cornuta (Kolmogorov-Smirnov Test $\mathrm{Z}=2.23, \mathrm{p} \leq$ $0.001)$. In $D$. spinulosum, larger individuals showed higher mean values of I/C than smaller individuals. Differences between smaller and larger individuals were significant only for $D$. spinulosum (KolmogorovSmirnov Test, $\mathrm{Z}=2.46, \mathrm{p} \leq 0.001$ ) but not for $C$. cornuta.

\section{Discussion}

Adult females of T. decipiens attacked, captured, and ingested both cladoceran prey. These results are in concordance to some previous field studies on gut contents (Gras et al. 1971, Clarke 1978) which show that cladocerans species are part of the diet of some Thermocyclops species. Similarly, our results are consistent with the unique laboratory observations on feeding behavior of $T$. decipiens realized by Carvalho (1984). In this study, T. decipiens was identified as $T$. crassus (Reid 1989) and attacks and complete ingestions of medium size Daphnia individuals were repor- 
ted for populations from Brazilian water bodies. Similarly, values of ingestion rates of T. decipiens on studied prey were in the range of values found by Matsumura-Tundisi et al. (1990) in observations of predation of Mesocyclops species on cladoceran prey using small observational volume of water and short period of observation.

T. decipiens showed higher C/A values on C. cornuta than on D. spinulosum. These results are consistent with the known ability for escape of Diaphanosoma species (Kerfoot et al. 1980, Williamson 1983) and the limited capacity of acceleration and escape of Ceriodaphnia species (Li \& Li 1979). While Diaphanosoma exhibit a rapid powerful stroke of their second antennae allowing escape from attack volume of the predator, Ceriodaphnia species increase swimming speed as an escape response, although they tend to stay inside of volume attack of the predator. Recently Chang \& Hanazato (2003) have indicated that swimming behavior of single strokes in Diaphanosoma may be effective at avoiding fish predation (Drenner et al. 1978, Drenner \& McComas, 1980), but fail as a defense mechanism against some copepod species. Contrarily, our observations show that efficiency of this defense mechanism against attacks of $T$. decipiens is highly effective. Therefore, no generalization seem to be possible because efficiency of avoiding cyclopoid predation by Diaphanosoma involve species-dependent components as size, swimming pattern or swimming speed of predators which must be considered in comparisons.

In our study, smaller individuals did not show higher C/A for cyclopoid copepods than larger individuals in the same cladoceran species. This is in contrast with the finding of Chang \& Hanazato (2003) and Lapesa et al. (2002). For C/A, it is clear that ability to swim faster, especially during escape situations, may be directly correlated to body size (Drenner et al. 1978, Drenner \& McComas 1980). It is also clear that mechanical disturbances produced by faster and larger bodies may be stronger, thereby allowing prey to be detected more precisely for mechanoreceptors of cyclopoid copepods (Williamson 1986). Consequently, cyclopoids would be able to optimize their attacks and increase the capture efficiency of larger individuals, as in the case of $D$. spinulosum. Differences in body size of $C$. cornuta seem to be not great enough to promote differences in swimming speed and mechanical signals detected by predator.

In the absence of a specialized escape behavior, strength and shape of prey body may determine I/C by cyclopoid copepods feeding on different prey species (Williamson 1986, Roche 1987, 1990). While, C. cor- nuta has a rotund body and a thick cuticule (Matsumura-Tundisi et al. 1990), Diaphanosoma species have a long cylindrical body and a soft carapace (Williamson 1983). Usually, soft body prey are ingested more easily than prey with hard body (Williamson 1983, Roche 1990), while prey with rotund bodies, such as Ceriodaphnia, seem difficult to handle by predators, thereby increasing probabilities of escape ( $\mathrm{Li} \& \mathrm{Li} 1979)$. According to these previous findings, we expected higher $\mathrm{I} / \mathrm{C}$ values for $D$. spinulosum than for $C$. cornuta. However, this hypothesis was confirmed only for larger individuals. In smaller individuals, $\mathrm{I} / \mathrm{C}$ values indicate that beside body strength, other factors are important in determining I/C among different species. Similarly, in the same species, I/C values did not increase in smaller individuals. Contrarily, ours results showed that abilities of $T$. decipiens to grasp $C$. cornuta did not change significantly with prey body size, but these abilities decreased to grasp smaller individuals of $D$. spinulosum. Thus, the thick cuticule of $C$. cornuta seems to be effective against $T$. decipiens even in smaller individuals. Williamson (1986) found a similar situation for Daphnia spp and Mesocyclops edax. The absence of differences between smaller and larger individuals in this case resulted from high invulnerability of prey species associated with predator difficulties handling hard carapace. Low efficiency of T. decipiens to manipulate smaller Diaphanosoma is not easy to explain, at least at the level of resolution of our observations. Similarly to other cyclopoid copepods (Williamson 1986, Chang \& Hanazato 2003), attack pattern of $T$. decipiens on Diaphanosoma species indicate that attacks occur primarily on the head and second antennae. Copepods grasp prey by the anterior end, typically near the base of second antennae or by the antennae, and ingest the anterior part of the body first (Williamson 1986). In smaller individuals, alometric reduction on size of these structures perhaps makes it difficult to handle by copepods and probability of escape of prey may increases.

Although some studies have indicated that no differences in swimming behavior of prey and cyclopoid copepod predators were found using observational chambers of different volume (Chang \& Hanazato 2003). Observations in laboratory could be affected for use of small volume of water which can alter behavior of predator and prey because probabilities of encounters increases (Gerritsen \& Strickler 1976, Williamson 1986). Therefore, extrapolation of these results to natural populations could be limited to situations of high probability of encounter between predators and prey, such as cyclopoid predators feeding on swarm of prey. 
The volume of our observational chamber and number of prey used for us represent a similar or lower ratio prey : predator than ratios used in previous studies made by direct observation or using video-camera (e.g. Williamson 1986, 1987, Roche 1990, Chang \& Hanazato 2003). Thus, comparison among our results and previous studies are possible but considering differences in identity, origin, and size both prey and predator.

With these limitations, we can conclude that in observational conditions of high probability of encounter between predator and prey, C. cornuta and D. spinulosum exhibit relatively low post-encounter vulnerabilities to predation by omnivorous T. decipiens. In this situation, the ability of escape, as well as the strength and shape of carapace seem partially explain differences of vulnerability among these species. Our results suggest that intensity of mechanical perturbations and other size-dependent factors, but not body size alone, could be important in determining post-encounter prey vulnerability among individuals of a same species. However, we need more detailed studies involving other cladoceran prey and using experimental designs, in which the changes of behavior or abilities of predator with decreasing observational volume and increasing prey density are considered.

\section{Acknowledgement}

This research was financially supported by a grant to CL from Consejo Desarrollo Cientifico y Humanistico of Universidad del Zulia (VAC-CONDES 1358-00). CL acknowledges the Universidad del Zulia and Baylor University for financial support as Visiting Research Professor during his stay at Baylor University when this paper was finished. Special thanks to O.T. Lind for invitation to work in his laboratory and revision and comments on the first manuscript. Also, we are grateful to M. Villalobos by assistance in laboratory observations and C.T. Filstrup for improving grammar English. Valuable comments and suggestions from two anonymous referees greatly improved an early version of this paper.

\section{References}

Blumenshine S \& Hambright K. 2003. - Top-down control in pelagic systems : a role for invertebrate predation. Hydrobiologia, 491, 347-356.

Carvalho M.A.J. 1984. - On feeding behavior of Thermocyclops crassus. Crustaceana Suppl., 7, 122-125.

Chang K. \& Hanazato T. 2003. - Vulnerability of cladoceran species to predation by the copepod Mesocyclops leuckarti : laboratory observations on the behavioral interactions between predator and prey. Freshwat. Biol., 48, 476-484.

Clarke N. 1978. - The food of adult copepods from lake Kainji, Nigeria. Freshwater Biol., 8, 321-326.

Drenner R. \& McComas S. - 1980. The roles of zooplankter escape ability and fish size selectivity in the selective feeding and impact of plantivorous fish. Pages 587-591 in Evolution and Ecology of Zooplankton Communities. Kerfoot W.C. (eds). University Press of New England, Hanover, New Hampshire. U.S.A.
Drenner R., Strickler J. \& O’Brien W. 1978. - Capture probability : the role of zooplankter escape in the selective feeding of planktivorous fishes. J. Fish. Res. Board Can., 35, 1370-1373.

Fagan W. 1997. - Omnivory as a stabilizing feature of natural communities. Am. Nat., 150, 554-567.

Gerritsen J. \& Strickler J. 1976. - Encounter probabilities and community structure in zooplankton : a mathematical model. J. Fish. Res. Board Can., 34, 73-82.

Gilbert J. \& Williamson C. 1978. - Predator-prey behavior and its effect on rotifer survival in associations of Mesocyclops edax, Asplanchna girodi, Polyarthra vulgaris and Keratella cochlearis. Oecologia, 37, 13-22.

Gliwicz Z.M. \&. Umaña G. 1994. - Cladoceran body size and vulnerability to copepod predation. Limnol. Oceanogr., 39, 419-424.

González E. 1998. - Natural diet of zooplankton in a tropical reservoir (El Andino reservoir, Venezuela). Verh. Int. Verein. Limnol., 26, 1930-1934.

Gras R., Iltis A. \& Saint-Jean L. 1971. - Biologie des crustacés du Lac Tshac II. Regime alimentaire des entomostracés planctoniques. Cah. O.R.S.T.O.M. Hydrobiol., 5, 285-296.

Hart D. 2002. - Intraguild predation, invertebrate predators, and trophic cascades in lake food webs. J. Theor. Biol., 218, 111-128.

Holt R. \& Polis G.1997. - A theoretical framework for intraguild predation. Am. Nat., 149, 745-764.

Infante A. 1978. - Natural food of herbivorous zooplankton of Lake Valencia (Venezuela). Arch. Hydrobiol., 82, 347-358.

Jamieson C. 1980. - The predatory feeding of copepodid stages IIIadult Mesocyclops leuckarti (Claus). Pages 518-537.

Kerfoot W.1978. - Combat between predatory copepods and their prey : Cyclops, Epischura and Bosmina. Limnol. Oceanogr., 23, 1089-1102.

Kerfoot W., Kellog D \& Strickler J. 1980. - Visual observations of live zooplankters evasion, escape and chemical defenses. Pages 1027. in Evolution and Ecology of Zooplankton Communities. Kerfoot W.C. (eds). University Press of New England, Hanover, New Hampshire. U.S.A.

Lapesa S., Snell T., Fields D. \& Serra M. - 2002. Predatory interactions between a cyclopoid copepod and three sibling rotifer species. Freshwat. Biol., 47, 1685-1695.

Li J. \& Li H. 1979. - Species specific factors affecting predator-prey interactions of the copepod Acanthocyclops vernalis with its natural prey. Limnol. Oceanogr., 24, 613-626.

López C. 1994. - Egg-stock and clutch size of two species of Thermocyclops Kiefer in a tropical reservoir. Verh. Inter. Verein. Limnol., 25, 2329-2332.

López, C., Villalobos M. \& González E. 2001. - Estudios sobre el zooplancton de los embalses de Venezuela : Estado actual y recomendaciones para investigaciones futuras. Ciencia, 9, 217-234.

Matsumura-Tundisi T., Rietzler A., Espindola A. \& Tundisi J. 1990. - Predation on Ceriodaphnia cornuta and Brachionus calyciflorus by two Mesocyclops species coexisting in Barra Bonita reservoir (SP, Brazil). Hydrobiologia, 198, 141-151.

Moriarty D., Darlington J., Dunn I., Moriarty M. \& Tevlin M. 1973. Feeding and grazing in Lake George, Uganda. P. Roy. Soc. Lond. B. Bio., 184, 299-319.

Reid J. 1989. - The distribution of species of the genus Thermocyclops (Copepoda, Cyclopoida) in the western hemisphere, with description of $T$. parvus, new species. Hydrobiologia, 175, 149174.

Rocha O., Sendacz S. \& Matsumura-Tundisi T. 1995. - Composition, biomass, and productivity of zooplankton in natural lakes and reservoirs in Brazil. Pages 151-166 in Limnology in Brazil. Tundisi J., Picudo C. \& Matsumura-Tundisi T. (eds), ABC/SBL. Rio de Janeiro. 
Roche K. 1987. - Post-encounter vulnerability of some rotifer prey types to predation by the copepod Acanthocyclops robustus. Hydrobiologia, 147, 229-233

Roche K. 1990. - Some aspects of vulnerability to cyclopoid predation of zooplankton prey individuals. Hydrobiologia, 198, $153-$ 162.

Soto L., López C. \& Bello C. 1994. - Química del Agua del Embalse Socuy, Estado Zulia, Venezuela. Bol. Centro Inv. Biol., 28, 1 21.

Ueda H. \& Reid J. 2003. - Copepoda : Cyclopoida. Genera Mesocyclops and Thermocyclops. Guides to the identification of the macroinvertebrates of the continental waters of world. 20. Backhuys Publishers. 318 p.
Williamson C. \& Gilbert J. 1980. - Variation among zooplankon predators : the potential of Asplanchna, Mesocyclops and Cyclops to attack, capture and eat various rotifers prey. Pages : 509-517. in Evolution and Ecology of Zooplankton Communities. Kerfoot W.C. (eds). University Press of New England, Hanover, New Hampshire. U.S.A.

Williamson C. 1983. - Behavioral interactions between a cyclopoid copepod and its prey. J. Plankton Res., 5, 701-711.

Williamson C. 1986. - The swimming and feeding behavior of $\mathrm{Me}$ socyclops. Hydrobiologia, 134, 11-19.

Williamson C. 1987. - Predator-prey interactions between omnivorous diaptomid copepods and rotifers : role of prey morphology and behavior. Limnol. Oceanogr., 32, 167-177. 